NOTICE: this is the author's version of a work that was accepted for publication in Mathematics and Computers in Simulation. Changes resulting from the publishing process, such as peer review, editing, corrections, structural formatting, and other quality control mechanisms may not be reflected in this document. Changes may have been made to this work since it was submitted for publication. A definitive version was subsequently published in Mathematics and Computers in Simulation, 81, 7, 2011 DOI

10.1016/j.matcom.2010.05.022 


\title{
MODELLING SUSTAINABILITY
}

\author{
Vladislav Todorov \\ Curtin University of Technology and University of Forestry \\ 10 Kliment Ohridski blvd., 1756 Sofia, Bulgaria, e-mail: vtodorov@ltu.bg
}

\author{
Dora Marinova* \\ *Corresponding author \\ Curtin University of Technology, GPO Box U1987, Perth, WA 6845, Australia, e-mail: \\ d.marinova@curtin.edu.au, phone: +61 89266 9033, fax: +61 892669031
}

\begin{abstract}
The article presents a general classification of the models being developed in the area of sustainability arguing that the existing models represent the historical conceptualisation of sustainability starting from environmental constraints and moving towards economic valuation and social behaviour and policies. Coupled with computer power, sophisticated models with a varying levels of complexity have also been developed (static/dynamic; local/global; specific/general). However as any model is a simplification of the complex reality, the main purpose of any sustainability modelling (and the newly emerging area of sustainometrics) should be to allow dynamic representation, including the co-evolution of the sustainability systems and the role of humans as sustainability guardians.
\end{abstract}

\section{Introduction}

The concept of "sustainability" has been associated with a wide range of human activities related to the use of resources, including natural, human and financial, implying long-term continuity and ability to carry on with these activities indefinitely [27]. According to Hasna [18], sustainability refers to a development of all aspects of human life affecting sustenance. Since the mid 1970s the term has been laden with value judgements about justice in the distribution and use of resources. This was started by the World Council of Churches during its 1975 Assembly in Nairobi [8], followed by the publication of Our Common Future (or the Brundtand Report) by the World Commission on Environment and Development in 1987, the 1992 United Nations' Earth Summit in Rio de Janeiro (which adopted Agenda 21) and continued through the adoption of the Millennium Development Goals by the United Nations' General Assembly in 2000 and the 2002 World Summit in Johannesburg. The 1997 Kyoto Protocol linked to the United Nations Framework Convention on Climate Change entered into force in 2005 and currently the international community is expecting further changes following the 2009 Copenhagen Climate Change negotiations. A lot of this political debate has been fuelled by the evidence originating from the academic and scientific world as to what impacts climate change and environmental deterioration have on human and other communities.

The 2001 World Congress "Challenges of a Changing Earth 2001" in Amsterdam organised by the International Council for Science (ICSU), the International GeosphereBiosphere Program (IGBP), the International Human Dimensions Program on Global Environmental Change (IHDP) and the World Climate Research Program (WCRP) proclaimed the birth of a new academic field, namely sustainability science, with strong roots in the environmental aspects of the sustainability concept [23]. On the other hand, by that time economists, philosophers and ethicists among others had already started the 
pursuit of understanding concepts such as the limits to growth [29], steady-state economics [10], weak and strong sustainability [33] and deep ecology [41, 50]. Environmental and resource economics grew as an area that was posing significant challenges to the understanding of the "interactions between environmental quality and the economic behavior of individuals, groups of people and firms" [38: 224]. The United Nations 2005 World Summit in New York (a follow-up of the 2000 Millennium Summit) reaffirmed that the new area of knowledge development requires to be grounded in the "interdependent and mutually reinforcing pillars” [50: 12] of simultaneously achieving economic prosperity, social development and environmental protection.

Hence, we have witnessed the establishment of a highly complex, vibrant and holistic new area of scientific endeavour which will be bringing together scholarship and practice [7] shaping human understanding, behaviour, innovation, decision-making and actions in the years to come. Described as "use-inspired basic research" [6: 1737], this science is still in the process of defining and developing its analytic and scientific underpinning, approach, tools, objectives, aims and tasks.

A major part of the efforts to further knowledge in this area has been the application of computer-based models that attempt to capture mainly environmental and economic aspects of the sustainability imperatives, such as computable general equilibrium, econometric, optimisation and hybrid models or emissions and land use models [35]. They all rely on the availability of data as well as on methodologies for valuation of the environment informed by recent developments in economics. What is apparent is the lack of a new approach to handling what Dovers [11: 2] describes as "the fundamental, structural inconsistencies between natural and human systems. The causes of sustainability problems lie deep in patterns of consumption and production, settlement and governance” that any modelling, be it boosted by the unprecedented computer power, so far has left untouched.

The scale and time dimensions of the current sustainability problems are unprecedented in at least three aspects: firstly, never before has humanity experienced such profound effects from globalisation; secondly, the importance of the human-made world and the laws that govern it, such as the market mechanisms, has grown to become comparable to that of the natural systems; and thirdly, the tools that society and science have developed to handle policy formulation, decision-making and governance (mainly informed by discipline-based assessment methodologies) have been focused on the short to medium term and therefore inadequate from an intergenerational sustainability perspective. A new area of research, namely sustainometrics, is emerging charged with the task to model and measure sustainability [45, 46, 47], but the required new scientific approaches, tools and methodologies are still in their infancy.

The focus of this article is to analyse the current state of play in the development of models used to describe sustainability (or sustainable development; for simplicity, we use the terms interchangeably). We present a general typology of models used for the representation and study of sustainability along five major categories of models, namely quantitative models (including mathematical, statistical, data-based, econometric and computer simulation), pictorial visualisation (including the Venn diagram, graphic representation, pictures and drawings), conceptual models (representing particular concepts and theories), standardising models (including indicators, benchmark values and targets) and physical models (a smaller or larger physical version of the object/system that allows visualisation and further investigation). Following this, a new approach to modelling 
sustainability is put forward. It builds on the strengths and constantly increasing capacity of information technology and the potential of information theory to transcend the discipline boundaries between economics, environmental and social sciences.

\section{Characteristics of models}

According to Franck [13], the ten main general characteristics of scientific models are that they:

(1) provide a simplified representation of the reality;

(2) represent what is considered to be essential to this reality;

(3) are testable;

(4) under the scientific approach, the models themselves become the object of study;

(5) are conceptual;

(6) allow the possibility of measurement and calculation;

(7) allow explanation of the reality;

(8) are a fictive representation of the reality;

(9) represent systems;

(10) are isomorphic (in fact, also homomorphic) to the systems that they represents.

Some of these characteristics (e.g. 1, 2, 5, 7 or 8) are more general than others (e.g. 3, 4, 6, 9 and 10). On the other hand, some types of models represent some of these characteristics better than others.

Each of the five major categories of sustainability models listed above generally satisfies Franck's [13] requirements for a model to be scientific; however the implications from using a particular category are very different. For example, a purely theoretical model can be very strong as a conceptual tool but lack the fully developed tools to be testable and measurable. Alternatively, a system of indicators can play a very valuable role as a fictive representation of the reality which allows measurement and calculation but lack the depth in conceptualisation and explanation of the phenomena that they represent. Moreover, such a system of indicators are likely to also become management targets and detract from the real phenomenon in favour of its model. It is often the case that the modelling of a particular phenomenon or system is done through a combination of models from the above categories as each category serves a different purpose and a different audience.

The aim of this article is to discuss a range of methodological problems related to models of sustainability. It is an attempt to comment on the conceptual frameworks behind the models, their applicability and capacity to generate knowledge.

From a policy perspective, Boulanger and Bréchet [4] outline five most important methodological criteria that need to be taken into account for modelling the challenging issues of sustainability, namely: C1 - interdisciplinary approach; C2 - managing uncertainty; C3 - a long-range or intergenerational point of view; C4 - global-local perspective; and C5 - stakeholders’ participation.

Against this background of achievements in the art of modelling and expectations as to what it can deliver, the paper comments on the types of models that sustainometrics needs to develop in its capacity of information-based co-evolutionary theory that deals with global virtual realities with a time horizon span larger than a century in order to allow for global intelligent systems to emerge that facilitate a move towards a more sustainable human presence on the planet Earth. 


\section{Review of sustainable development models}

There have been numerous ways of representing sustainable development in a model that encapsulates this extremely complex concept and a new way of thinking. This section is an attempt to briefly capture some of these efforts (please refer also to Table 1) while the section to follow expands on what we perceive to be the major features of any modelling that would be in a position to properly reflect the essence of sustainability.

[Insert Table 1 about here]

\subsection{Pictorial visualisation models}

According to the World Conservation Union [52], the three dimensions of sustainability (economic, social and environmental) are represented either as pillars, embedded circles or in the popular Venn diagram of three overlapping circles. The latter model stresses the importance of the intersection between the three areas (see Figure 1). These models clearly emphasise the need for interdisciplinary and transdiciplinary (e.g. [18]) approach to understanding sustainability but their explanatory power is much weaker in relation to the other four criteria put forward by Boulanger and Bréchet [4]. Generally, these are popular static models with limited informative value but powerful in terms of reaching a broad audience.

\section{[Insert Figure 1 about here]}

\subsection{Quantitative models}

From a policy-making perspective, Boulanger and Bréchet describe six types of quantitative models, namely "macro-econometric models, computable general equilibrium models, optimization models, system dynamics models, probabilistic or Bayesian network models (this category also includes risk assessment models based on influence diagrams) and multi-agent simulation models” [4: 340-341].

Economic models represent a special sub-class of the quantitative models. In fact, this area has been extremely active in academic pursuit generating models representing various economic concepts, ranging from neo-classical, evolutionary, ecological economics to neoRicardian [12]. These models have attempted to find ways of embracing uncertainty and dealing to a various degree of success with long-range perspectives. Despite this, they have been poorly equipped to accommodate a holistic perspective, address the local-global perspective or acknowledge the need for stakeholders' participation.

A recent example of a policy-endorsed quantitative model is the Irish Sustainable Development Model ISus [26, 35] which is based on an environmental input-output approach [35]. It "involves a matrix representation of the economy in order to predict the effect of changes in one industry on others, while at the same time modelling the effect of this interaction on consumers, the government and foreign suppliers” [36: 158]. The matrix representation used is as follows:

$$
\mathrm{M}=\mathrm{BX}=\mathrm{BLY}
$$

which relates emissions $\mathrm{M}$ (e.g. by substance or outputs, such as waste) to production $\mathrm{X}$ via $B$ (the emission coefficients matrix, that is, emission or waste per unit of production). Alternatively, it can also be linked to final consumption via BL which is the Leontieff 
reverse of production $\mathrm{X}$ into consumption BY [36]. For a particular emission l, such as carbon dioxide, sulphur dioxide, carbon monoxide and volatile organic compounds (or output, such as landfill or biodegradable waste), equation (1) becomes:

$$
\mathrm{M}_{\mathrm{I}}=\mathrm{b}_{\mathrm{i}, 1} \mathrm{X}_{1}+\mathrm{b}_{\mathrm{i}, 2} \mathrm{X}_{2}+\ldots \mathrm{b}_{\mathrm{i}, \mathrm{n}} \mathrm{X}_{\mathrm{n}} \square \quad \forall \mathrm{l}
$$

Real 1990-2006 data analysis for Ireland is used in ISus covering more than 25 potential pollutants (including air, water and waste) generated in 20 economic sectors [26] which allows for policy forecasts to be drawn. The measurements of the variables are physical values in relative terms to the euro (e.g. g/€) or reciprocally, euros per physical value (e.g. $€ / \mathrm{g})$.

A different approach to quantitative modelling is the use of fuzzy logic to represent the relationships and principles governing the aspects of sustainability organised around rules and inputs/outputs of knowledge bases which "are expressed symbolically in the form of words or phrases of a natural language and mathematically as linguistic variables and fuzzy sets. Examples of IF-THEN rules used in the model are:

IF HUMS is good AND ECOS is bad, THEN OSUS is average” [1: 151-152], where OSUS is overall sustainability, derived from measures of human (HUMS) and ecological (ECOS) sustainability. Normalisation is subsequently used to facilitate fuzzy computations.

Another example of quantitative models are the interactive game-based multi-agent simulation models, where "the interaction between economic and ecologic dynamic systems is analysed with a multi-player dynamic game, in which each player invests and allocates available capital to the production or consumption of natural resources and goods, and evaluates the outcome of all players' actions as well as the reactions of the ecosystem" [39: 371]. They allow for policy strategies, such as cooperation, coalition, negotiation and competition, to be explored providing informed outcomes to decision-makers. For instance, the output vector $\mathrm{V}$ can be presented as a function of the input vector $\mathrm{C}$ (e.g. costs), the system state $x$ (e.g. resources) and a preference matrix $p$ [39]:

$$
\mathrm{V}=\mathrm{f}(\mathrm{x}, \mathrm{p}, \mathrm{C})
$$

It is interesting to note that lessons from game models like this, learned be it through theoretical analysis or computer simulation, suggest that highly competitive strategies within a state of limited resources, which is the case with almost any resource on this planet, lead to a situation where everyone looses, though a few players may have a temporary competitive advantage. Cooperation appears as a logical alternative with potential benefits for all involved.

A common characteristic of the quantitative models is the fact that they remain dominated by the discipline from where they have originated, be it environmental science, engineering or economics. They do deliver some valuable insights but their application and importance need to be put into perspective.

\subsection{Physical models}

The use of physical models for sustainability has been restricted mainly to its environmental component. They have been applied for water (e.g. [19]), energy, buildings, in urban design, for recreation of habitat [24], for handling of pollution, $\mathrm{CO}_{2}$ (e.g. New Zealand's zero emissions housing, http://www.zeroplus.net.nz/) and toxicity (e.g. [22]), in implementing industrial ecology, to mention a few examples. 
Physical models are very specific and predominantly local. The purpose of their construction is to reduce the uncertainty; however their time span is quite restricted. They allow for a participatory approach and interdisciplinary perspectives, but by nature are only a fragmented part of the global sustainability system and can rarely serve this main purpose of modelling for sustainability.

\subsection{Conceptual models}

This category of models is very broad and is linked to humanity's waking up to the limits of its natural environment and the negative impacts that population and its "development" have been having on it. They started with the work of the Club of Rome [29] or more recently [31], went through the conceptualisation of the implications from the use of nuclear weapon ("nuclear winter", see Turco et al. [49]) and from ozone depletion and the ozone hole (Litfin [25]) to go through the various futurist scenarios such as the ones developed by the World Business Council for Sustainable Development (e.g. Speth [42]), to the work on global warming and climate change (e.g. IPCC [20]). Another example of a powerful theoretical idea that has crossed the boarders of many disciplines and is also contributing to understanding sustainability is the evolutionary concept (Costanza et al. [9]).

The long-term and intergenerational perspective has been an important trigger for these models and the majority of them contain a warning element and signals for alertness, in some cases threats and fears. Many are also ideologically laden and have been plaid heavily on the political agenda, occasionally allowing stakeholders' participation. With emphasis on the global, concrete solutions for local problems have been difficult to find within the theoretical models and some implied consequences have been the cause of despair and ideological wars.

The inability of these models to manage uncertainty has been their weakest point and this has allowed for wide differences of opinion to emerge. A recent example of this is the socalled climate change denialism (e.g. Begley [2]). On the positive side of things, the conceptual models have generated wide debates and triggered policy responses.

\subsection{Standardising models}

The development and use of sustainability indicators is an area of active research and practice that has received a lot of attention, including many interactive web-based applications. It has produced a variety of lists and descriptions such as the 2006 United Nations list of Indicators of Sustainable Development which includes a total of 96 indicators (http://www.un.org/esa/dsd/dsd_aofw_ind/ind_index.shtml) or sets applicable at community (e.g. Hart [17]), corporate [21], national [40], state [15] or local government level (e.g. http://www.stirling.wa.gov.au/). They can cover particular activities, such as sustainable consumption or production. There have also been attempts to develop a holistic or aggregate indicator to measure sustainability, such as the genuine savings indicator [16], gross national happiness [5] or ecological footprint [37]. The measurements of the variables also widely differ depending on the adopted approach.

The aim for the majority of indicators is to somehow assign a value or a number that describes the complexity between social, environmental and ecological health. According to Yunis [53], "(t)hey are signals of current issues, emerging situations or problems, need for action and results of actions". They allow to gauge the performance of the system (Bell and Morse [3]). These models can accommodate a very specific local-global perspective 
and the process of their development can be participatory. Despite the intention for a longterm perspective, the practicality of all indicators is such that they represent a good snapshot for the particular moment and only if records are kept and data processed can they provide longer trends. Representatives of different disciplines can be drawn into the process, however the desired outcome has to allow for crossing borders between the disciplines and the areas of immediate interest.

Irrespectively as to how much progress is made towards measuring and assessing sustainability or unsustainability, there are many signs just in front of human eyes that can perfectly capture what the situation is. As Donella Meadows said: "We can learn at least as much about sustainability by turning our eyes away from numbers and noticing the soil washing down the streams, the clearcuts where forests once stood, the changing climate, the smell of city air, the places on earth too contaminated to live in or too desperate to be safe in, and the hectic emptiness of our lives. Some day we may have numbers to measure these blatant signals of unsustainability. In the meantime we can admit that we already know" (http://www.grist.org/article/sustainability/).

This acknowledgement of the severity and pervasiveness of the problem requires a new perspective and a new way of thinking about sustainability. It requires a stronger focus on the process itself rather than centring attention on its components, states, outcomes or aspirations. This is not to say that all of the above are unimportant; they are useful guiding tools but the nature of the sustainability puzzle at the moment lies in the processes that will generate a different way for humanity to relate to its hosting planet Earth and fully embrace its role of a steward and guardian of the resources and health of the natural environment.

\section{Approach to modelling sustainable development}

According to Murcott [30], and later adopted by the OECD, sustainable development can be understood within interaction conceptual frameworks that describe the interactions between the pairs of the humanity- economy-nature triad as well between all three of them. This approach as well as the bulk of the models refereed to in the previous section reveal some inherent difficulties associated with what we describe as methodological eclecticism that is not in a position to serve the needs of sustainable development. The following major considerations explain why:

- the approach is based on shorter trends than the long-range intergenerational needs;

- the fragmentation (often representative of the Western science approach) does not allow for a holistic view and understanding.

The approach that is needed requires simultaneous integration of economic, social and ecological knowledge in order to understand development not in an antagonistic way but as human evolution within a constantly changing and evolving natural world. Hence, we need a co-evolutionary paradigm in order to grasp the global problems of humanity, which at the moment present themselves as antagonist relationships and contradictions. In fact, this is the first time in history that we are witnessing problems of such a scale as, for example, climate change, that threaten the long-term future of life on Earth. Its origin and causes show that the human race has become such a mighty power that is capable of bringing out of balance what have been for millennia self-regulating geo- and bio-systems. Many see the Apocalypse approaching and believe that humanity itself is opening the seven seals. 
Sustainable development is the new emerging area of hope against these doom and gloom projections. It is likely to become a fundamental feature of the global development processes and a point of reference for joint consideration and interpretation of the unity in the development of nature and society.

Based on the co-evolutionary paradigm (e.g. Norgaard [34]), it is possible to model the interactions within the global system "humanity-global economy-nature". The important point is that all three should be modelled and analysed simultaneously in terms of their global interactions. In other words, a model: (1) should not be representing only one of the components (e.g. the economy) against the other two; and (2) should allow a study of the conflict and risk factors together with the resulting changes of transformation and coadaptation that shape the co-evolution process. Hence, sustainable development is not only a macroeconomic concept; it is not only about nature conservation either. It can be about social advancement but again cannot happen in isolation from nature and the economy. Sustainable development is a development that synchronises and harmonises economic, social and ecological processes.

Since the $20^{\text {th }}$ century, globalisation has become a distinctive feature of development affecting the economy (and making it global), society (with emerging global consciousness and shared global problems) and the environment (with the effects of pollution, for example, becoming of global importance). In fact, sustainable development is becoming a "globalising" development which does not contravene but reinforces and synchronises these processes. The planet Earth can only support such development.

An adequate model of sustainable development cannot build only on the existing understanding of society and nature. Humans have also created what can be described as "second nature", i.e. the human-made material world which by size and importance has become comparable to the global natural systems. It not only acts as a buffer between humans and nature (see Figure 2) but has also become the main objective of human development. Following its own developmental logic and laws, this "second nature" ironically is now threatening the planet's nature.

[Insert Figure 2 about here]

A model of this global sustainable development system is that of a meta-system (4) which is in a state of dynamic balance $\oplus$ :

$$
\mathbf{G S}=\mathbf{H} \oplus \mathbf{E} \oplus \mathbf{N}
$$

where $\mathrm{H}$ is humanity; $\mathrm{E}$-global economy and $\mathrm{N}$ - the global natural environment (see also Figure 3).

\section{[Insert Figure 3 about here]}

The following three characteristics, informed by the co-evolution principles, are important for model (4):

(1) Heterogeneity - i.e. the three global systems have very different governing laws, rules, pathways and influencing forces. At the local scale, heterogeneity is expressed in specific socio-ecological systems in which ecological, social and cultural elements are represented as a whole through the complex and intricate interactions of geographic, biological and anthropomorphic factors. Therefore the global system is not just a complex of global phenomena of a different nature, but 
complex and mutually dependent arranged in pace separate socio-natural agglomerates.

(2) Equality - i.e. need to holistically integrate different priorities. It emphasised the deep connection and direct and multilateral interaction between each of the components and the rest. Examples of this are any of the global problems that society currently faces, e.g. climate change.

(3) Human stewardship - i.e. the leading role that humanity has in transforming, maintaining and/or sustaining the planet Earth.

Below is a possible typology of models of sustainable development based on the approach described above.

(1) Time-related (t-models):

- $\quad$ Static $\left(t^{s}\right.$-models);

- Dynamic $\left(t^{d}\right.$-models).

Criterion: They model (analyse/forecast) the state of sustainability or assess/predict the processes of sustainable development.

(2) Place-related (s-models):

- Global ( $s^{g}$-models);

- Regional ( $s^{r}$-models).

Criterion: They model the state of sustainability/sustainable development processes depending on their scale and/or localisation. The global closed models are insignificantly affected by the scale of the system, while the regional models are open and reflect the specifics of particular regional systems.

(3) Scale-related ( $r$-models):

- General ( $r^{g}$-models);

- Specific ( $r^{s}$-models).

Criterion: They model sustainable development of systems which differ according to composition and structure.

What we have put forward elsewhere is the need for the new science of sustainometrics to be informed by two transdisciplinary theories, namely co-evolution and information theory [48] which will generate models that are dynamic, global and general. Such models will need to represent:

- Real processes of system interactions;

- Spontaneously generated information about the changes in the meta-system in an environment shaped by the interactions between its three components;

- Application of the law of information relevance, which is based on the system's hierarchy, nature and complexity.

Information theory, its new paradigms, principles and approaches can form the basis for the development of such models for global sustainable development. Its advances coupled with the enormous power of information technology and informatics so far have not been properly used to assist any integrated modelling attempts. The complexity and size of the 
problems that sustainability poses however demand further new developments within information theory and its applications.

In light of the urgency of the climate change agenda in particular, it is not enough for a few individual researchers to endorse such a new approach to modelling sustainability; such a shift needs to be accepted by the research community as a whole. We are witnessing severe disappointment with existing practices and incapability to continue with the current standards; however an agreement on what needs to change is yet to be recognised. Only dynamic, global and general modelling can inform proper decision-making and policy solutions.

There is no doubt that the range of sustainability models used so far (please refer to Table 1) will continue to have their applications and place in understanding different aspects of the sustainability puzzle. What sustainometrics is aiming to achieve however is a way of modelling sustainability that transcends the problem not only with the three constituting domains (economic, social and environmental) but also with the time, place and scale perspective of any debates, decisions and policies.

This type of models is yet to be developed. For example, they can assist in creating a GISbased global virtual model of the Earth that allows forecasting and predicting as well as assisting in building scenarios and trajectories in the opportunity spaces of a future global virtual reality. The use of space sattelites, remote sensing and mathematical modelling has already been suggested in the case of sustainable development in the Aral Sea region [44]; however, a global perspective is pressingly needed.

\section{Conclusions}

According to Costanza et al. [9: 547], “(m)odels are analogous to maps... they have many possible purposes and uses, and no one map or model is right for the entire range of uses". Sustainability, including the transition to a more sustainable way of living and doing things, should be an overarching issue for any policy making. There is ample evidence that humanity has reached the Earth's capacity to neutralise the negative environmental impacts from its economic activities. Climate change, loss of biodiversity, fresh water availability, acidification of oceans, nitrogen and phosphorus saturation of soils, stratospheric ozone depletion, chemical pollution, arable land use are all environmental aspects that require constant monitoring and understanding. Modelling is a powerful way to develop specific understanding of these issues.

On the other end of the spectrum are social problems ranging from population growth, poverty, resource distribution, urbanisation, illiteracy, health to inequity, injustice, human and natural rights, politics, ethics, world orders and domination. They are all cushioned in what we have termed industrial development and the processes of globalisation that it has triggered. The economics of production and consumption, including the development and application of new technologies, has become a powerful decision making tool for the "homo economicus" [43]. Sustainable development aims to integrate all these considerations and create working realistic solutions at the local and global level.

Sustainability is a powerful agenda charged with the task not only to find such practical ways out now; it is also here to stay as humanity constantly negotiates its position, actions and responsibility within the limits of planet Earth. The five groups of models discussed here, namely quantitative, pictorial, conceptual, physical and standardising, have been used by researchers, policy makers, politicians, professionals, educators among others to fulfil this role. However, the presented analysis of the models of sustainable development 
clarified the need for a new type of models that can further the domain of sustainometrics, namely the knowledge base for modelling and measuring sustainability.

These models are only possible with the current advances in information technology accompanied by the transdisciplinary developments in information theory and coevolutionary methodology. They are based on the understanding that information is a limitless resource that can be also exploited over and over again. Such models, based around a virtual model of the Earth, should be simultaneously time-, scale- and placerelated by being dynamic, global and general in their characteristics. They will have the purpose to create a map that not only presents the co-evolution of the global system but also allows humanity the ability to fulfil its stewardship obligations on this stunningly beautiful planet that we and future generations call home.

\section{Acknowledgments}

The authors wish to acknowledge the financial support of the Australian Research Council for making this research possible. They are also grateful for the feedback received from the participants and referees of the international scientific conferences on Management and Sustainable Development, Yundola, Bulgaria and the 2009 Congress of the Modelling and Simulation Society of Australia and New Zealand ModSim09 where some of the original ideas and related concepts were first presented. The comments of two anonymous referees were very valuable and we want to acknowledge their help for improving the quality of the paper.

\section{References}

[1] L.A. Andriantiatsaholiniaina, V.S. Kouikoglou, Y.A. Phillis, Evaluating strategies for sustainable development: Fuzzy logic reasoning and sensitivity analysis, , Ecological Economics 48 (2004) 149-172.

[2] S. Begley, Global warming: The truth about denial, Newsweek, 7 August 2007, http://www.newsweek.com/id/32482 (accessed 08.06.2009).

[3] S. Bell, S. Morse, Sustainability Indicators: Measuring the immeasurable?, Earthscan, London, 1999.

[4] P.-M. Boulanger, T. Bréchet, Models for policy-making in sustainable development: The state of the art and perspectives for research, Ecological Economics 55 (2005) 337-350.

[5] A.C. Brooks, Gross National Happiness: Why Happiness Matters for America and How We Can Get More of It, Basic Books, New York, 2008.

[6] W.C. Clark, Sustainability science: A room of its own. Proceedings of the National Academy of Science USA 104 (2007) 1737-1738.

[7] W.C. Clark, N.M. Dickson, Sustainability science: The emerging research program. Proceedings of the National Academy of Science USA, 100(2003) 8059-8061.

[8] J.B. Cobb, Sustainability: Economics, Ecology, and Justice, Orbis, Maryknoll, NY, 1992.

[9] R. Costanza, L. Wainger, C. Folke, K.-G. Mäler, Modelling complex ecological economic systems, BioScience 43(1993) 545-555.

[10] H.E. Daly, Steady-State Economics, second ed. Island Press, Washington, DC, 1991.

[11] S. Dovers, Scaling governance and institutions for sustainability, in: Academic Forum, Network of Regional Government for Sustainable Development (nrg4SD), Regional Governance for Sustainability, Fremantle, Western Australia, 2003. 
[12] S. Faucheux, D. Pearce, J. Proops (Eds), Models of Sustainable Development, Edward Elgar, Brookfield, Vt, 1996.

[13] R. Franck (Ed.), The Explanatory Power of Models, Springer, Berlin, 2002.

[14] E. Giannetti Vícios Privados, Benefícios Públicos? A Ética na Riqueza das Nações, Companhia das Letras, Lisbon, 1993.

[15] Government of Western Australia, Hope for the Future: The Western Australian State Sustainability Strategy, Department of the Premier and Cabinet, Perth, 2003.

[16] K. Hamilton, G. Atkinson, D. Pearce, Genuine Savings as an Indicator of Sustainability, CSERGE Working Paper GEC 97-03 (1997) www.uea.ac.uk/env/cserge/pub/wp/gec/gec_1997_03.pdf (accessed 08.05.2009).

[17] M. Hart, Guide to Sustainable Community Indicators, $2^{\text {nd }}$ ed., Hart Environmental Data, North Andover, MA, 1999.

[18] A.M. Hasna, Dimensions of sustainability, Journal of Engineering for Sustainable Development: Energy, Environment, and Health, 2(2007), 47-57.

[19] D. Hellström, U. Jeppsson, E. Kärrman, A framework for systems analysis of sustainable urban water management, Environmental Impact Assessment Review, 20(2000) 311-321.

[20] Intergovernmental Panel on Climate Change (IPCC), Climate Change 2007: The Physical Science Basis, Contribution of Working Group I to the Fourth Assessment Report of the Intergovernmental Panel on Climate Change, Cambridge University Press, Cambridge, 2007.

[21] T. Jackson, P. Roberts, A Review of Indicators of Sustainable Development: A Report for Scottish Enterprise Tayside, University of Dundee, Dundee, http://www.trp.dundee.ac.uk/library/pubs/set.html\#2.3 [30 March 2010]

[22] S. Karlsson, Closing the technospheric flows of toxic metals: Modeling lead losses from a lead-acid battery system for Sweden, Journal of Industrial Ecology, 3(2008) 23-40.

[23] R. Kates, W. Clark, R. Corell, J. Hall, C. Jaeger, I. Lowe, J. McCarthy, H.-J. Schellnhuber, B. Bolin, N. Dickson, S. Faucheux, G. Gallopin, A. Grubler, B. Huntley, J. Jager, N. Jodha, R. Kasperson, A. Mabogunje, P. Matson, H. Mooney, Sustainability science, Science 292(2001), 641-642.

[24] C.D. Levings, Knowledge of fish ecology and its application to habitat management, in: B.J. Groulx, D.C. Mosher, J.L. Luternauer, D.E. Bilderback (Eds), Fraser River Delta, British Columbia: Issues of an Urban Estuary, Geological Survey of Canada, Bulletin 546(2004) 213-236.

[25] K.T. Litfin, Ozone Discourses: Science and Politics in Global Environmental Cooperation, Columbia University Press, New York, 1994.

[26] S. Lyons, R.S.J. Tol, Ireland's Sustainable Development Model (2006-SDM-LS11-M2), STRIVE Report 47, Environmental Protection Agency, Wexford, Ireland, http://www.epa.ie/downloads/pubs/research/econ/STRIVE_47.pdf [28 March 2010]

[27] D. Marinova, N. McGrath, Transdisciplinarity in teaching and learning sustainability, in: G. Banse, I. Hronszky, G. Nelson (Eds), Rationality in an Uncertain World, Edition Sigma, Berlin, 2005, pp 275-285.

[28] D. Marinova, M. Raven, Indigenous knowledge and intellectual property: A sustainability agenda, Journal of Economic Surveys 20(2006) 587-606.

[29] D. Meadows, D.L. Meadows, J. Randers, W. Behrens, The Limits to Growth, Universe Books, New York, 1971.

[30] S. Murcott, Sustainable development: A meta-review of definitions, principles, criteria indicators, conceptual frameworks and information systems, Annual 
Conference of the American Association for the Advancement of Science, IIASA Symposium on Sustainability Indicators, Seattle, WA, 1997.

[31] Netherlands Environmental Assessment Agency (PBL), Growing within Limits: A Report to the Global Assembly 2009 of the Club of Rome, 2009, PBL publication number 500201001, Bilthoven, Holland.

[32] P. Newman, J. Kenworthy, Sustainability and Cities: Overcoming Automobile Dependence, Island Press, Washington, DC, 1999.

[33] E. Neumayer, Weak versus Strong Sustainability: Exploring the Limits of Two Opposing Paradigms, Edward Elgar, Cheltenham, UK, 2003.

[34] R.B. Norgaard, Development Betrayed: The End of Progress and a Coevolutionary Revisioning of the Future, Routledge, London, New York, 1994.

[35] J. O’Doherty, K. Mayor, R.S.J. Tol, Irish Sustainable Development Model (ISus): Literature Review, Data Availability and Model Design, The Economic and Social Research Institute Working Paper 186(2007), Dublin, http://www.esri.ie/UserFiles/ publications/20070403121154/WP186.pdf [28 March 2010]

[36] J. O’Doherty, R.S.J. Tol, An environmental input-output model for Ireland, The Economic and Social Review, 38 (2007),157-190.

[37] W. Rees, Ecological footprints and appropriate carrying capacity: What urban economics leaves out, Environment and Urbanisation, 4(1992) 121-130.

[38] S. Rousseau, Journal evaluation by environmental and resource economists: A survey, Scientometrics 77(2008) 223-233.

[39] J. Scheffran, The dynamic interaction between economy and ecology: Cooperation, stability and sustainability for a dynamic-game model of resource conflicts, Mathematics and Computers in Simulation, 53 (2000) 371-380.

[40] Scottish Enterprise, Guidelines for Sustainable Development Appraisal, Scottish Enterprise Network, 1999.

[41] G. Sessions (Ed.), Deep Ecology for the Twenty-First Century, Shambhala Publications, Boston, 1995.

[42] J.G. Speth, Red Sky at Morning: America and the Crisis of the Global Environment, Yale University Press, New Haven and London, 2004.

[43] C. Spretnak, The Resurgence of the Real: Body, Nature and Place in a Hypermodern World, Routledge, New York, 1999.

[44] U. Sultangazin, Information systems based on space monitoring for solution of some problems of sustainable development, Mathematics and Computers in Simulation, 67 (2004) 279-290.

[45] V. Todorov, System sustainability and development sustainability: Modelling problems (Is E-conometrics of sustainable development possible?), Management and Sustainable Development, 18(2006) 136-140 (in Bulgarian).

[46] V. Todorov, D. Marinova, Models of Sustainability, MODSIM 2009 International Congress on Modelling and Simulation, Modelling and Simulation Society of Australia and New Zealand, Cairns, Australia, 2009, pp 1216-1222

[47] V. Todorov, D. Marinova, Sustainometrics: Measuring sustainability, MODSIM 2009 International Congress on Modelling and Simulation, Modelling and Simulation Society of Australia and New Zealand, Cairns, Australia, 2009, pp 1223-1229.

[48] V. Todorov, D. Marinova, Information theory perspective on modelling sustainability, 43rd Hawaii International Conference on Systems Sciences, Hawaii, USA, The Institute of Electrical and Electronics Engineers (IEEE), CD ROM, 2010. 
[49] R.P. Turco, O.B. Toon, T.P. Ackerman, J.B. Pollack, C. Sagan, Nuclear winter: Global consequences of multiple nuclear explosions, Science, 222(4630) (1983) 1293-1300.

[50] United Nations (UN), 2005 World Summit Outcome, General Assembly. http://www.who.int/hiv/universalaccess2010/worldsummit.pdf [2 May 2009]

[51] N. Witoszek, A. Brennan (Eds), Philosophical Dialogues: Arne Naess and the Progress of Ecophilosophy, Rowman and Littlefield, Lanham, MD, 1999.

[52] World Conservation Union (IUCN), The Future of Sustainability: Re-thinking Environment and Development in the Twenty-first Century, 2006, http://cmsdata.iucn.org/downloads/iucn_future_of_sustanability.pdf [8 May 2009].

[53] E. Yunis, Indicators to measure sustainability in tourism, 7th International Forum on Tourism Statistics, Stockholm, 2004, www.tourismforum.scb.se/papers/PapersSelected/SD/Paper37WTO/ Stockholm_Indicators_June04.doc [8 May 2009]. 


\section{Figure captions:}

Figure 1. Examples of the Venn diagram

a. For example, Newman and Kenworthy [32]

b. IUCN [52]

Figure 2. A buffer model of the global system; Source: Giannetti [14]

Figure 3. Co-evolutionary model 